\title{
Perception of Nurse Experts on the Contribution of Nursing Interventions to NOC Nursing Outcomes in General Hospitals in Korea
}

\author{
Byoungsook Lee, RN, PhD'
}

The purpose of this study was to identify the perception of nurse experts on the contribution of nursing interventions to Nursing Outcomes Classification NOC nursing outcomes. A nursing outcome is a nursing-sensitive patient outcome primarily affected by nursing interventions. As one of the standardized language systems of nursing outcomes, the NOC must be examined for applicability before it is used in Korea. Data were collected in February and March 2003 using a 5-point Likert scale. For data collection, 230 quality improvement (QI) or quality assurance (QA) nurses from general hospitals in Korea were asked to rate the extent that nursing interventions contribute to each of the NOC nursing outcomes (2000) in their hospitals. Ninety-six nurses from 63 hospitals responded and the response rate was $41.7 \%$.

Mean scores for perception of contribution of nursing interventions to each of the NOC nursing outcomes ranged from 2.18 to 4.54. Vital Signs Status had the highest score $(M=4.54)$, and Abuse Recovery: Financial, the lowest score $(\mathrm{M}=2.18)$. Of the seven NOC domains, the mean score was highest for Physiologic Health $(\mathrm{M}=$ 3.91) and lowest for Community Health $(M=2.92)$. Of the 29 NOC classes, the mean score for perceived contribution was highest for Metabolic Regulation $(\mathrm{M}=4.32)$ and lowest for Community Well-Being $(\mathrm{M}=2.92)$. Participants perceived that nursing interventions in general hospitals in Korea contributed, at least to a certain extent, to most of the NOC nursing outcomes. Based on these results, NOC should have relatively good applicability in Korea.

Key Words : Nursing outcome, Nursing intervention, NOC

\section{PURPOSE AND BACKGROUND}

Today, while the demands of health care consumers are increasing, the cost of health care is rising rapidly. This situation is forcing health care professionals and managers to emphasize the effectiveness of health care and to monitor the quality and cost of the health care that they provide (Bond \& Thomas, 1991). The effectiveness of health care can be evaluated by measuring health care outcomes. Patient outcomes are the most important health care outcomes. Thus, health care organizations and professionals in Korea are attempting to measure patient outcomes in order to evaluate the effectiveness of the health care they provide (Lee \& Kwon, 1996). Nursing plays an important role in improving patient outcomes, and certain patient outcomes are more sensitive to nursing interventions than others (Bloch, 1975; Gallant \& McLane, 1979; Lang \& Marek, 1991; Higgins, McCaughan, Griffiths \& Carr-Hill, 1992; Griffith, 1995). 
Patient outcomes that are sensitive to nursing interventions are called nursing outcomes and nursing outcomes reflect the practice and standards of the nursing profession (Johnson, Maas \& Moorhead, 1997).

Measurement of nursing outcomes is essential for evaluation of the performance, quality, and cost of nursing practice (Maas, 1998). This evaluation can provide empirical data about the effectiveness of nursing interventions, which in turn provides evidence of the usefulness of nursing care (Hill, 1999). Moreover, the evaluation of nursing outcomes can help to clarify the purpose and focus of nursing practice and provide further opportunities for empirical studies that are indispensable for the development of the nursing profession (Retting, 1991). By presenting evidence on the usefulness of nursing interventions, the measurement of nursing outcomes can also be used to improve the reimbursement rates for nursing practice (Johnson, Maas \& Moorhead, 2000).

Since the 1970s, one of the most important issues in nursing has been the development of standardized nursing language systems and several systems have been developed. Nursing Outcomes Classification (NOC), a standardized language system of patient outcomes that are sensitive to nursing interventions was developed in the U.S. NOC has a three-level taxonomy and the 260 nursing outcomes in NOC have been classified into seven domains and 29 classes (Johnson, Maas \& Moorhead, 2000). Because they can be used as nursing goals, NOC makes it possible to evaluate individual nursing care. NOC has been approved world wide in its usefulness for the development of nursing research, practice, and administration (Johnson \& Maas, 1998; Moorhead, Head, Johnson, \& Maas, 1998; Prophet \& Delaney, 1998).

Nursing is a health profession that plays an important role in improving patient outcomes, and research to identify the contribution of nursing interventions to nursing outcomes is very important. Particularly, it is meaningful to examine these relationships using a standardized language. Although NOC's general adaptability to nursing in Korea has been explored in several recent studies, few studies have been done to investigate the relationship between nursing interventions and NOC nursing outcomes. Such studies are vitally important because of the marked differences between American and Korean nursing practice. As nursing outcome research becomes more prevalent in Korea, study of how nursing interventions contribute to each NOC nursing outcomes becomes significant. For the nursing outcome studies, nursing interventions provided to patients to help solve their nursing problems must be considered because a nursing outcome is generally achieved by implementing several nursing interventions, not just one. So, this study was done to identify the contribution of nursing interventions to each NOC nursing outcome in general hospitals in Korea by having nurse experts assess this contribution.

\section{DEFINITION OF TERMS}

A nursing outcome is defined as a change in the patient's health status caused by nursing interventions (Johnson, Maas \& Moorhead, 1997). For this study, 260 nursing outcomes from NOC (2000) were used. Nursing interventions are defined as nursing activities that are provided to solve a nursing problem. In this study, nursing interventions are the nursing activities generally provided to solve nursing problems of patients in general hospitals in Korea.

\section{METHODS}

\section{Participants and setting}

230 Quality Improvement (QI) or Quality Assurance (QA) nurses working in 130 general hospitals in Korea participated in this study. They were selected because they are the nurses mainly in charge of doing research on patient outcomes in Korea. They were considered to have sufficient expertise and experience with nursing outcomes to make a definitive assessment. A list of the participants was made from the membership list of the Korean Quality Improvement Nurse Society. Of the 230 participants who were sent questionnaires by mail, 96 from 63 hospitals responded. The response rate was $41.7 \%$.

\section{Instrument}

The 260 nursing outcomes in NOC (2000) were used. The nursing outcomes were translated into Korean using as a base previous publications including one book and one study (Park, Kim, \& Cho, 2000; You, 2001). For easier and a more correct understanding, the translation was validated by ten nurses who had master's degrees and three or more years of nursing experience in tertiary hospitals. Appropriate changes were made. On the questionnaires, participants were asked to estimate the extent to which they thought nursing interventions con- 
tributed to each of the NOC nursing outcomes. Participants were asked to rate each outcome on a fivepoint Likert scale, from five points meaning 'definitely contributes' to one point meaning 'no contribution'.

\section{Data collection and analysis}

Distribution and collection of the questionnaires was done by mail between February and March 2003. The SPSS Win 10.0 program was used for data analysis. Mean scores and standard deviations were derived for the 260 nursing outcomes, 29 classes, and 7 dimensions. ANOVA was used to analyze differences in the mean scores for classes and dimensions according to the demographic characteristics of the participants.

\section{RESULTS}

\section{Characteristics of the participants}

The mean age of the participants was 41.06 (6.66) years and $55.2 \%$ of the participants were over 41 years old. The mean hospital experience of the participants was 17.97 (6.98) years; the majority of the participants (43.8\%) had been employed in hospitals for between 11 and 20 years. About $59 \%$ of the participants had master or doctoral degrees. About $44 \%$ of the participants were head nurses, and $33.3 \%$ were middle nurse managers. Most of the participants (71.9\%) worked in large general hospitals with 500 or more beds (Table 1).

Participants' perception of the contribution of nursing interventions to NOC nursing outcomes

Mean scores for contribution ranged from 4.54 to 2.18. The NOC nursing outcome perceived to have had the highest contribution from nursing interventions was

Table 1. Characteristics of the Participants $(\mathrm{N}=96)$

\begin{tabular}{|c|c|c|c|}
\hline \multicolumn{2}{|c|}{ Characteristics } & $\mathrm{N}$ & $\%$ \\
\hline \multirow{4}{*}{ Age } & i 30 yrs & 10 & 10.4 \\
\hline & $31-40$ yrs & 32 & 33.3 \\
\hline & $i^{\wedge} 41$ yrs & 53 & 55.2 \\
\hline & missing & 1 & 1 \\
\hline \multirow[t]{4}{*}{ Job Experience } & $\mathrm{i}^{-10}$ yrs & 14 & 14.6 \\
\hline & $11-20$ yrs & 42 & 43.8 \\
\hline & i 21yrs & 39 & 40.6 \\
\hline & missing & 1 & 1 \\
\hline \multirow[t]{4}{*}{ Education } & Diploma & 12 & 12.5 \\
\hline & Baccalaureate & 23 & 24.0 \\
\hline & Master/Doctoral & 57 & 59.4 \\
\hline & missing & 4 & 4.2 \\
\hline \multirow[t]{4}{*}{ Position } & Staff Nurse & 20 & 20.8 \\
\hline & Head Nurse & 42 & 43.8 \\
\hline & Middle manager & 32 & 33.3 \\
\hline & missing & 2 & 2.1 \\
\hline \multirow[t]{3}{*}{ Hospital } & $<500$ beds & 26 & 27.1 \\
\hline & i 500 beds & 69 & 71.9 \\
\hline & missing & 1 & 1.0 \\
\hline
\end{tabular}

Table 2. Perception of Participants on the Contribution of Nursing Interventions to Each of NOC Nursing Outcomes in Korean Hospitals: Ten Highest and Ten Lowest Nursing Outcomes

\begin{tabular}{|c|c|c|c|c|}
\hline Contribution of nursing intervention & Rank & Nursing Outcome & Mean & SD \\
\hline \multirow{10}{*}{10 Highest } & 1 & Vital Signs Status & 4.54 & .71 \\
\hline & 2 & Knowledge: medication & 4.46 & .60 \\
\hline & 3 & Safety Behavior: Fall Prevention & 4.42 & .75 \\
\hline & 4 & Blood Glucose Control & 4.34 & .69 \\
\hline & 5 & Self-Care: Parenteral Medication & 4.32 & .75 \\
\hline & 6 & Self-Care: Non-Parenteral Medication & 4.29 & .71 \\
\hline & 7 & Self-Care: Toileting & 4.28 & .69 \\
\hline & 8 & Self-Care: Oral Hygiene & 4.28 & .68 \\
\hline & 9 & Respiratory Status: Airway Patency & 4.28 & .86 \\
\hline & 10 & Knowledge: Diabetes Management & 4.27 & .83 \\
\hline \multirow{10}{*}{10 Lowest } & 260 & Abuse Recovery: Financial & 2.18 & 1.08 \\
\hline & 259 & Abuse Cessation & 2.62 & 1.05 \\
\hline & 258 & Abuse Recovery: Sexual & 2.69 & 1.10 \\
\hline & 257 & Abuse Protection & 2.71 & 1.07 \\
\hline & 256 & Sexual Identity: Acceptance & 2.77 & 1.09 \\
\hline & 255 & Community Risk Control: Lead Exposure & 2.79 & 1.24 \\
\hline & 254 & Sexual Functioning & 2.79 & 1.06 \\
\hline & 253 & Community Health: Immunity & 2.83 & 1.07 \\
\hline & 252 & Family Normalization & 2.85 & 1.15 \\
\hline & 251 & Family Integrity & 2.88 & 1.09 \\
\hline
\end{tabular}


Vital Signs Status $(\mathrm{M}=4.54)$, followed by Knowledge: Medication $(\mathrm{M}=4.46)$, Safety Behavior: Fall Prevention $(\mathrm{M}=4.42)$, Blood Glucose Control $(\mathrm{M}=4.34)$, and SelfCare: Parenteral Medication ( $\mathrm{M}=4.32)$. The nursing outcome perceived to have had the lowest contribution from nursing interventions was Abuse Recovery: Financial $(\mathrm{M}=2.18)$. The ten highest rated and the ten lowest rated nursing outcomes are shown in (Table 2).

Of the ten highest-rated nursing outcomes, four were in the Self-Care class in NOC's Functional Health domain, three were in the Health Knowledge and Behavior domain, and the other three were in Physiologic Health. Of the ten lowest-rated outcomes, six were in the Family Health domain (including four in the Family Member Health Status class). Two outcomes related to sexuality were also included in the ten lowest-rated nursing outcomes: Sexual Identity: Acceptance and Sexual Functioning.

Mean scores at the domain and class level can be found in (Table 3). In the seven NOC domains, the highest mean score was found in Physiologic Health ( $\mathrm{M}=$ 3.91), followed by Health Knowledge and Behavior (M = 3.61), While the lowest mean score was found in Community Health $(\mathrm{M}=2.92)$. In the 29 NOC classes, the highest mean score was found in Metabolic Regulation ( $\mathrm{M}=4.32)$, followed by Therapeutic Response $(\mathrm{M}=4.24)$, And the lowest class mean score was found in Community Well-Being $(\mathrm{M}=2.92)$.

Significant differences were found in the mean scores at the domain and class level, according to educational status of the participants and size of hospitals in which the participant was working. At the domain level, for example, there were significant differences in mean scores for Perceived Health $(\mathrm{F}=4.56, \mathrm{p}=0.013)$ and Community
Table 3. Perception of Participants on the Contribution of Interventions for Each NOC Domain and Class $(\mathrm{N}=96)$

\begin{tabular}{|c|c|c|c|}
\hline \multirow{2}{*}{ Domain } & \multirow{2}{*}{ Class } & \multicolumn{2}{|c|}{ Score } \\
\hline & & Mean & $\mathrm{SD}$ \\
\hline \multirow[t]{5}{*}{ Functional Health } & & 3.60 & 0.54 \\
\hline & A-Energy Maintenance & 3.41 & 0.69 \\
\hline & B-Growth \& Development & 3.20 & 0.66 \\
\hline & C-Mobility & 3.75 & 0.59 \\
\hline & D-Self-Care & 4.00 & 0.62 \\
\hline \multirow[t]{11}{*}{ Physiological Health } & & 3.91 & 0.50 \\
\hline & E-Cardiopulmonary & 3.79 & 0.77 \\
\hline & F-Elimination & 4.01 & 0.62 \\
\hline & G-Fluid \& Electrolytes & 4.16 & 0.68 \\
\hline & H-Immune Response & 3.93 & 0.60 \\
\hline & I-Metabolic Regulation & 4.32 & 0.68 \\
\hline & J-Neurocognitive & 3.55 & 0.67 \\
\hline & K-Nutrition & 3.76 & 0.57 \\
\hline & a-Therapeutic Response & 4.24 & 0.61 \\
\hline & L-Tissue Integrity & 3.92 & 0.58 \\
\hline & Y-Sensory Function & 3.39 & 0.96 \\
\hline \multirow[t]{5}{*}{ Psychosocial Health } & & 3.29 & 0.64 \\
\hline & M-Psychological Well-Being & 3.36 & 0.68 \\
\hline & N-Psychosocial Adaptation & 3.48 & 0.57 \\
\hline & O-Self-Control & 3.23 & 0.70 \\
\hline & P-Social Interaction & 3.16 & 0.85 \\
\hline Health Knowledge & & 3.61 & 0.54 \\
\hline \multirow[t]{4}{*}{ \& Behavior } & Q-Health Behavior & 3.51 & 0.55 \\
\hline & R-Health Beliefs & 3.45 & 0.80 \\
\hline & S-Health Knowledge & 3.90 & 0.59 \\
\hline & T-Risk Control \& Safety & 3.61 & 0.68 \\
\hline \multirow[t]{3}{*}{ Perceived Health } & & 3.50 & 0.66 \\
\hline & U-Health \& Life Quality & 3.42 & 0.75 \\
\hline & V-Symptom Status & 3.57 & 0.65 \\
\hline \multirow[t]{4}{*}{ Family Health } & & 3.22 & 0.64 \\
\hline & W-Family Care-giver Status & 3.39 & 0.68 \\
\hline & Z-Family Member Health Status & 3.21 & 0.63 \\
\hline & X-Family Well-Being & 3.04 & 0.92 \\
\hline \multirow[t]{3}{*}{ Community Health } & & 2.92 & 0.99 \\
\hline & b-Community Well-Being & 2.92 & 1.09 \\
\hline & c-Community Health Protection & 2.98 & 1.05 \\
\hline
\end{tabular}

Table 4. Perception on the Contribution to NOC Domains According to Educational Level of Participants and Size of Hospitals (N=96)

\begin{tabular}{|c|c|c|c|c|c|c|}
\hline \multirow{2}{*}{ Domain } & \multicolumn{3}{|c|}{ Educational Status } & \multirow{2}{*}{$\mathrm{F}$} & \multirow{2}{*}{$\mathrm{P}$} & \multirow{2}{*}{ Post-hoc } \\
\hline & Dipl.(1) & Bacc. (2) & Mast./Doc. (3) & & & \\
\hline Perceived Health & 3.84 & 3.18 & 3.54 & 4.56 & .013 & $(2)<(1)$ \\
\hline \multirow[t]{3}{*}{ Community Health } & 3.58 & 2.77 & 2.83 & 3.33 & .040 & $(2)<(1)$ \\
\hline & \multicolumn{3}{|c|}{ Hospital Size } & & & \\
\hline & $<5$ & & i 500 beds & & & \\
\hline Functional Health & \multicolumn{2}{|c|}{3.80} & 3.52 & 5.11 & .026 & \\
\hline Psychosocial Health & \multicolumn{2}{|c|}{3.58} & 3.20 & 5.71 & .019 & \\
\hline Health Knowledge \& Behavior & \multicolumn{2}{|c|}{3.85} & 3.54 & 5.47 & .022 & \\
\hline Perceived Health & \multicolumn{2}{|c|}{3.74} & 3.42 & 4.33 & .040 & \\
\hline Family Health & \multicolumn{2}{|c|}{3.52} & 3.12 & 7.41 & .008 & \\
\hline Community Health & \multicolumn{2}{|c|}{3.35} & 2.80 & 5.83 & .018 & \\
\hline
\end{tabular}

Dipl.: Diploma, Bacc.: Baccalaureate, Mast./Doc.: Master or Doctoral 
Health $(\mathrm{F}=3.33, \mathrm{p}=0.040)$, according to the educational status of the participants. There was also a difference according to hospital size, as shown in Functional Health $(\mathrm{F}=5.11, \mathrm{p}=0.026)$, Psychological Health $(\mathrm{F}=5.71$, $\mathrm{p}=0.019)$, Health Knowledge and Behavior $(\mathrm{F}=5.47$, $\mathrm{p}=0.022)$, Perceived Health $(\mathrm{F}=4.33, \mathrm{p}=0.040)$, Family Health $(\mathrm{F}=7.41, \mathrm{p}=0.008)$, and Community Health $(\mathrm{F}=5.84, \mathrm{p}=0.018)$ (Table 4).

At the class level, significant differences were found in the mean scores of six classes according to educational status, and 13 classes according to hospital size (Table 5). Participants with master's or doctoral degrees gave higher ratings than participants with baccalaureate degrees. Participants employed at larger hospitals (500 or more beds) rated the contribution of nursing interventions higher than participants from smaller hospitals.

\section{DISCUSSION}

Vital Signs Status, which is included in the Metabolism Regulation class of the domain Physiologic Health, received the highest score, followed by Knowledge: Medication, Safety Behavior: Fall Prevention, Blood Glucose Control, and Self-Care: Parenteral Medication. In previous researches, checking and monitoring vital signs for hospitalized patients has been reported as one of the most frequently performed nursing activities in Korea (Lee, 1992; Kim \& Baek, 1996; Park et al., 2001). According to Lee's research (1999), Vital Signs Status was also one of the most frequently studied patient outcomes in Korea. The results of this study support these earlier findings.

Providing and Monitoring medications have been important nursing activities in Korean hospitals (Kim \& Park, 1987; Kim \& Baek, 1996; Yim, 1998). So, providing information about medication for patients has been also regarded as an important nursing activity. The results of this study, in which Knowledge: Medication had the second highest score, support these earlier findings. Of the four self-care nursing outcomes included in the highest-rated outcomes, two involved medication, both parenteral and non-parenteral, and these results could have the same interpretation as the nursing outcome of Knowledge: Medication.

In this study, four of the ten highest rated outcomes are found in the Self-Care class of the Functional Health domain, and three in the Health Knowledge class of Health Knowledge \& Behavior. The remaining three outcomes are found in Physiologic Health. It was interesting that four nursing outcomes related to self-care were in-

Table 5. Perception on the Contribution to NOC Classes According to Educational Level of Participants and Size of Hospitals (N=96)

\begin{tabular}{|c|c|c|c|c|c|c|}
\hline \multirow{2}{*}{ Class } & \multicolumn{3}{|c|}{ Educational Status } & \multirow{2}{*}{$\mathrm{F}$} & \multirow{2}{*}{$\mathrm{P}$} & \multirow{2}{*}{ Post-hoc } \\
\hline & Dipl.(1) & Bacc. (2) & Mast./Doc. (3) & & & \\
\hline H-Immune Response & 4.32 & 3.95 & 3.84 & 3.30 & .042 & $(3)<(1)$ \\
\hline a-Therapeutic Response & 4.25 & 3.96 & 4.36 & 3.71 & .028 & $(2)<(3)$ \\
\hline P-Social Interaction & 3.70 & 2.94 & 3.10 & 3.55 & .033 & $(2)<(1)$ \\
\hline T-Risk Control \& Safety & 3.92 & 3.29 & 3.64 & 3.48 & .035 & $(2)<(1)$ \\
\hline U-Health \& Life Quality & 3.77 & 3.08 & 3.47 & 3.99 & .022 & $(2)<(1)$ \\
\hline \multirow[t]{3}{*}{ V-Symptom Status } & 3.92 & 3.30 & 3.58 & 3.68 & .029 & $(2)<(1)$ \\
\hline & \multicolumn{3}{|c|}{ Hospital Size } & & & \\
\hline & & $<500$ beds & $i^{\wedge} 500$ beds & & & \\
\hline A-Energy Maintenance & & 3.74 & 3.27 & 9.42 & .003 & \\
\hline J-Neurocognitive & & 3.92 & 3.42 & 10.81 & .001 & \\
\hline L-Tissue Integrity & & 4.21 & 3.83 & 8.46 & .005 & \\
\hline M-Psychological Well-Being & & 3.64 & 3.26 & 5.84 & .018 & \\
\hline N-Psychosocial Adaptation & & 3.71 & 3.40 & 5.77 & .018 & \\
\hline O-Self-Control & & 3.47 & 3.14 & 4.21 & .043 & \\
\hline P-Social Interaction & & 3.49 & 3.03 & 5.40 & .022 & \\
\hline Q-Health Behavior & & 3.82 & 3.40 & 11.56 & .001 & \\
\hline V-Symptom Status & & 3.88 & 3.46 & 7.97 & .006 & \\
\hline W-Family Care-giver Status & & 3.71 & 3.28 & 7.92 & .006 & \\
\hline X-Family Well-Being & & 3.44 & 2.91 & 6.39 & .013 & \\
\hline b-Community Well-Being & & 3.37 & 2.76 & 6.17 & .015 & \\
\hline c-Community Health Protection & & 3.40 & 2.85 & 5.36 & .023 & \\
\hline
\end{tabular}

Dipl.: Diploma, Bacc.: Baccalaureate, Mast./Doc.: Master or Doctoral 
cluded in the top ten because, in Korea, self-care has not traditionally been considered as valuable as in western countries, especially for hospitalized patients. It has been considered important in Korean culture to assist patients physically for their full hospitalization even though they are sufficiently capable of providing selfcare for themselves. As the nuclear family becomes increasingly prevalent, however, and western life style is increasingly adopted, self-care and independence are becoming more valuable. These lifestyle changes are inducing changes in the nursing environment, which can be observed in the results of this study. In nursing studies in Korea, Self-Care was reported as one of the most frequently studied patient outcomes (Lee, 1999).

The ten lowest-rated nursing outcomes included four that involve abuse (Abuse Recovery: Financial, Abuse Cessation, Abuse Recovery: Sexual, and Abuse Protection), three related to sexuality (Abuse Recovery: Sexual, Sexual Identity: Acceptance, and Sexual Functioning), and four related to community and family. These results are not surprising because this study focused on nursing interventions in acute care hospitals. However, the results also seemed to reflect our sociocultural background that has been closed, as far as communication about family violence and sexual life are concerned. These results could also imply that nursing practice in Korean hospitals is limited to the hospital settings and not connected to families and communities.

The scores were analyzed at both the domain level and the class level. The domain with the highest score was Physiological Health $(\mathrm{M}=3.91)$, and the class with the highest scoring was Metabolic Regulation $(\mathrm{M}=4.32)$. Because scores for management of diabetes and physical treatment were extremely high, scores of the classes and domains that include related nursing outcomes were also high. Previous studies have found that the measurable patient outcomes primarily affected by nursing care were mostly related to the physiological health of the patients and to physical treatment (Lang \& Marek, 1991; Higgins, McCaughan, Griffiths \& Carr-Hill, 1992).

The domain with the lowest score was Community Health, and class with the lowest score, Community Well-Being. These results are not surprising as participants were nurse experts in general hospitals and they were asked to rate the contribution of nursing interventions to nursing outcomes in hospital settings. These results may also suggest, however, that nursing interventions involving physical care of patients make a greater contribution to patient outcomes in hospitals than they do in community settings. Further research is necessary to explore the situation related to these results, in particular, when physical care is provided in community settings.

Education levels of the participants and the size of the hospitals where they were employed generated results that were statistically significant. In all of the domains and classes, for which there were significant differences according to educational levels, participants with master's or doctoral degrees generally gave higher scores than participants with baccalaureate or master degrees. Because it is not easy to identify the reasons for these findings, further research is required. Participants from hospitals with fewer than 500 beds generally gave higher scores than participants from hospitals with 500 or more beds. These results could be attributed to two main factors: the differences in the severity of the patients and the availability of resources. In Korea, most general hospitals with fewer than 500 beds are secondary hospitals, while those with 500 or more beds are more likely to be tertiary hospitals. Patients treated in tertiary hospitals tend to have more acute and complicated health problems than those in secondary hospitals. Consequently, the effect of nursing interventions may be more limited in tertiary hospitals because of the acuteness of the patients' condition. Also, as tertiary hospitals tend to have more resources available for patient care with the exception of nursing resources-more qualified health professionals, better equipment and supplies- outcomes related to nursing interventions might not be as apparent. O'Connell (2001) has pointed out that the nature of the health care organization and the condition of the patients were the two main factors affecting the relationship between nursing interventions and outcomes. She also cited the condition of the patients as the most important factor affecting patient outcomes.

This study had some limitations. Because the response rate was relatively low, it is difficult to generalize the findings. Furthermore, because various interpretations of the question posed to the participants were possible, careful interpretation of the findings is essential.

\section{CONCLUSION \& RECOMMENDATIONS}

The purpose of this study was to identify the extent to which nurse experts perceive nursing interventions as contributing to NOC nursing outcomes in general hospi- 
tals in Korea. The mean scores of the perceived contribution ranged from 4.54 to 2.18 . The nursing outcome that participants perceived to have received the highest contribution from nursing interventions was Vital Signs Status; the outcome perceived to have received the least was Abuse Recovery: Financial. Of the seven NOC domains, the mean score was highest in the Physiologic Health Domain and lowest in Community Health. Of the 29 NOC classes, the mean score was highest for Metabolic Regulation and lowest for Community WellBeing. Mean scores differed significantly, both at the domain level and the class level, depending on the educational status of the participants and the size of hospitals in which they worked.

This study revealed that most NOC nursing outcomes could be affected by nursing interventions in Korean hospitals. Based on these results, NOC could be said to have relatively good applicability in Korea. On those nursing outcomes that had the highest scores, research to identify the relationships between specific nursing interventions and specific outcomes is required. These outcomes could also be used as outcome indicators to evaluate the nursing practice in Korean hospitals.

\section{References}

Bloch, D. (1975). Evaluation of nursing care in terms of process and outcome: Issues in research and quality assurance, Nurs Res, 24(4), 256-263.

Bond, S., \& Thomas, L. H. (1991). Issues in measuring outcomes of nursing. J Adv Nurs, 16, 1492-1502.

Denehy, J. (1998). Integrating nursing outcomes classification in nursing education. J Nurs Care Qual, 12(5), 73-84.

Gallant, B. W., \& McLane, A. M. (1979). Outcome criteria: A process for validation of the unit level. J Nurs Adm, 9(1), 1421.

Griffith, P. (1995). Progress in measuring nursing outcomes. J Adv Nurs, 21, 1092-1100.

Higgins, M., McCaughan, D., Griffiths, M., \& Carr-Hill, R. (1992). Assessing the outcomes of nursing care. J Adv Nurs, 17, 561568.

Hill, M. (1999). Outcomes measurement requires nursing to shift to outcome-based practice. Nurs Adm Quatery, 24(1), 1-16.

Johnson, M., \& Maas, M. (1997). Iowa Outcomes Projects: Nursing Outcomes Classification (NOC). 1st ed. St. Louis: C.V. Mosby.

Johnson, M. \& Maas, M.(1998). The nursing outcomes classification. J Nurs Care Qual, 12(5), 9-20.
Johnson, M., Maas, M., \& Moorhead, S. (2000). Iowa Outcomes Projects: Nursing Outcomes Classification (NOC). 2nd ed. St. Louis: C.V. Mosby.

Keenan, G., \& Aquilino, M. L. (1998). Standardized nomenclatures: Keys to continuity of care, nursing accountability and nursing effectiveness. Outcomes Man Nurs Prac, 2(2), 81-86.

Kerr, P. (1999). Comparing two nursing outcomes reporting initiatives. Outcome Management Nurs Prac, 4(3), 144-149.

Kim, C. J., \& Park, J. W. (1987). A study for formulating criteria of patient classification system based on the analysis of direct nursing activity. J Korean Acad Nurs, 17(1), 9-23.

Kim, S. I., \& Baek, H. M. (1996). A Study on the Job Analysis of the Staff Nurses. Korean Nurs, 35(5), 110-117.

Lang, N. M., \& Marek, K. D. (1990). The classification of patient outcomes. J Prof Nurs, 6(3), 158-163.

Lang, N. M., \& Marek, K. D. (1991). The policy and politics of patient outcomes. J Nurs Qual Assurance, 5(2), 7-12.

Lee, B. S., \& Kwon, Y. S. (1996). Evaluation of outcome in nursing practice. J Korean Nurs Adm Acad Soc, 2(2), 59-71.

Lee, B. S. (1999). Patient Outcomes at Nursing Research in Korea. Keimyung J Nurs Sci, 3(1), 141-151.

Lee, Y. S. (1992). Measurement of the nursing workload in a special nursing unit-Tertiary hospital. Master's Thesis, Seoul National University.

Marek, K. D. (1989). Outcome measurement in nursing. J Nurs Qual Assur, 4(1), 1-9.

Mark, B. A. (1995). The black box of patient outcomes research. Image, 27(1), 42

Mass, M. L. (1998). Nursing's role in interdisciplinary accountability for patient outcomes. Outcomes Man Nurs Prac, 2(3), 92-94.

Moorhead, S., Head, B., Johnson, M. \& Maas, M. (1998). The nursing outcomes taxonomy: Development and coding. J Nurs Care Qual, 12(6), 56-63.

Retting, R. (1991). History, development, and importance to nursing of outcomes research. J Nurs Qual Assur, 5(2), 13-17.

O'Connell, B. (2001). Challenges of measuring and linking patient outcomes to nursing interventions in acute care settings. Nurs Health Sci, 3, 113-117.

Park, J. S., Koh, H. J., Kwon, Y. S., Kim, C. N., Park, Y. S., Park, C. J., Shin, Y. H., Lee, K. H., \& Lee, B. S. (2001). Activities of day and evening shifts nurses in a university hospital. Keimyung J Nurs Sci, 5(1), 169-183.

Park, H. A., Kim, J. E., \& Choi, I. S. (2000). Nursing Diagnosis, Intervention, Outcome Classification. Seoul, Seoul National University Press.

Prophet, C. M., \& Delaney, C. W. (1998). Nursing outcomes classification: Implications for nursing information systems and the computer-based patient record. J Nurs Care Qual, 12(5), 2129.

Yim, Y. Y. (1998). An analysis on nursing activity in a hospital. $J$ Korean Nurs Adm Acad Soc, 4(1), 73-88.

You, C. S. (2001). Construction of linkage database on nursing diagnoses, interventions, outcomes in abdominal surgery patients. Doctoral Dissertation, Chung Ang University. 